\title{
WELDABILITY EVALUATION OF API 5L X52 STEEL AND HEAT-AFFECTED ZONE (HAZ) SIMULATION USING GLEEBLE
}

\begin{tabular}{|c|c|}
\hline *Ashish Kumar & Rajneesh Kumar Gupta \\
Mechanical department & Engineering Department \\
ITS Engineering College Gr. Noida & National Metallurgical Laboratory, Jamshedpur \\
$*$ Corresponding author: ashuatcoer@gmail.com & \\
\hline
\end{tabular}

\begin{abstract}
The present paper emphases on the evaluation of weld ability of API 5LX52 steel plate material in thicknesses of 10 mm welded with Submerged Arc welding processes. Heat affected Zone (HAZ) is the most crucial part of a weld and achieving optimal material properties in HAZ is always a challenge for a welding engineer. Thermal cycle which HAZ experiences, was achieved using existing literature and was validated by making weld test coupons on few mild steel plates (assuming physical characteristics like density, thermal conductivity and specific heat capacity of mild steel and HSLA steel are same). While making these weld coupons, the thermal cycle in HAZ was obtained by inserting thermocouples at different regions of HAZ. These thermal cycles were further used to simulate the HAZ of HSLA \& Mild steel, using Gleeble. Characterization of welded as well as simulated specimens of mild steel was carried out by hardness testing and optical microscopy. Microstructure \& hardness of simulated specimens and actual welds were found to be matched.
\end{abstract}

Keywords - c HSLA, HAZ, Thermal Cycle, Microstructure, Hardness and Gleeble.

\section{INTRODUCTION}

In current years, the high strength low alloyed (HSLA) steels, having good mechanical properties and fine grain with the balance of both strength and toughness have been developed. Though, very good toughness value of a structural steel can be upset during welding procedures since toughness are very sensitive to microstructural change within heat-affected zone (HAZ)[1].The structural engineering alloys like HSLA undergo important changes in prior austenite grain sizes and the phase constituents during heat treatment processes and result in different microstructure and mechanical properties. The conventional understanding is that the larger grain sizes, associated with higher austenitising temperature, would generally result in a lower toughness [2].

To obtain a safe welded joint, therefore, it is necessary to know the effect of welding thermal cycles on weld HAZ toughness and determine the proper welding conditions. Generally, the weld coarse grained HAZ (CGHAZ) next to the fusion line having the lowest toughness among the various regions within a HAZ because of unfavorable microstructure [3].

In welding process, the weld CGHAZ experiences thermal cycle up to very high close to melting point temperature and fast cooling. This high peak temperature leads to significant growth of austenite grain and subsequent rapid cooling promotes relatively brittle microstructures in the weld CGHAZ, such as bainite, side-plates and martensite. Some research papers have suggested that, in addition to the thermal cycle, the CGHAZ experiences thermal stress and strain due to constraint by the thermally unaffected base metal during welding[4].

The present work involves the SAW technique with a view to increasing impact toughness and hardness of steel weldments while keeping ultimate tensile strength $490 \mathrm{MPa}$. The ultimate goal of this workfrom an industrial point of view was conducted as a first step towards determining the weldability characteristics of API 5L X52. A quantitative weldability evaluation of API 5L X52 was conducted through various laboratory scale physical simulation tests. The weldability tests mainly focused on the Heat Affected Zone (HAZ) regions, and quantifiable data was generated regarding the properties of characteristic HAZ regions. The weldability test results were used to understand the detailed microstructural evolution of API 5 L X52.

\section{MATERIALS AND EXPERIMENTAL APPROACH}

\section{A. Materials}

The experimental materials evaluated in this present work included API 5L X52 steel and Mild Steel were used. API 5L X52 steel plate was supplied by TATA STEEL Jamshedpur and Mild Steel by CSIR-NML Jamshedpur. Mild Steel plates of thickness $10 \mathrm{~mm}$ were cut from a long sheet having thickness $11 \mathrm{~mm}$ and API 5L X52 plates from $12 \mathrm{~mm}$ long sheet. Due to material limitation mild steel plates were used for SAW process (considering density, thermal conductivity and specific heat capacity are same as API 5L X52). API 5L X52 steel plates having Yield Strength $350 \mathrm{MPa}$ were used for simulation of weld HAZ

\section{B. Maintaining the Integrity of the Specifications}

In the present work mild steel plates were used for SAW process. Two mild steel plates of $10 \mathrm{~mm}$ thick and dimension of $300 \mathrm{~mm}$ in length and $100 \mathrm{~mm}$ in wide in the form of flat plates were taken. Welding wire (SAW1) of $3.25 \mathrm{~mm}$ diameter was used for this experiment. A single half V-butt joint with root face $4 \mathrm{~mm}$ and included angle $45^{\circ}$ is used for the welding task. Three thermocouples were Connected to specimen at 10 $\mathrm{mm}, 15 \mathrm{~mm}$ and $20 \mathrm{~mm}$ from center which measures the temperature at that point. Due to experimental limitation these thermocouples could not be inserted very close to the weld center line which is shown in Figure 1. All the thermocouples are connected with module which is connected to computer which measures the temperature by lab view program. 
ELK

\section{Asia Pacific Journals}

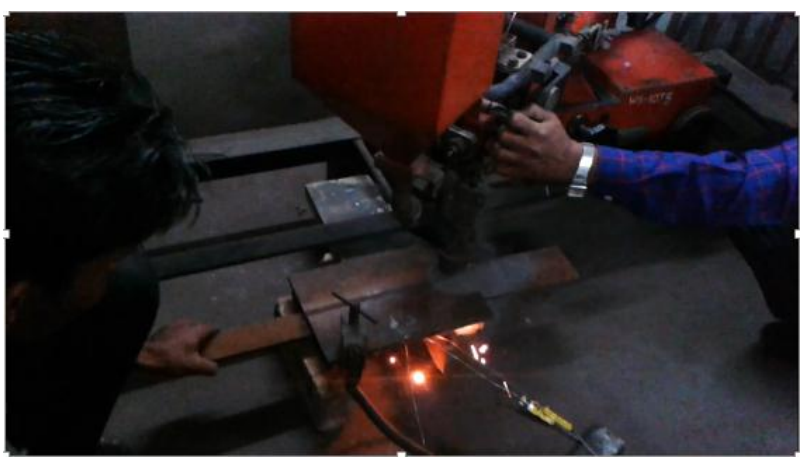

Fig. 1. Different thermocouple attachment with test weld

The chemical analysis of materials was carried out using DRS method and is given in table 1 .

Table 1 Chemical composition of base metal and electrode.

\begin{tabular}{|l|c|c|c|}
\hline Material & API 5L X52 & Mild Steel & SAW Wire \\
\hline $\mathrm{C}$ & 0.134 & 0.161 & 0.101 \\
\hline $\mathrm{Mn}$ & 0.810 & 1.510 & 1.200 \\
\hline $\mathrm{Mo}$ & 0.0076 & 0.0071 & 0.501 \\
\hline $\mathrm{Cr}$ & 0.032 & 0.028 & - \\
\hline $\mathrm{V}$ & 0.005 & 0.081 & - \\
\hline $\mathrm{Nb}$ & 0.0005 & $<0.0005$ & - \\
\hline $\mathrm{S}$ & 0.012 & 0.023 & 0.018 \\
\hline $\mathrm{P}$ & 0.019 & 0.027 & 0.018 \\
\hline $\mathrm{Si}$ & 0.0019 & - & 0.10 \\
\hline $\mathrm{Cu}$ & - & - & 0.25 \\
\hline
\end{tabular}

\section{Welding parameters}

The welding parameters were used for SAW Process which is shown in Table 2.

Table 2 Welding parameters for SAW Process

\begin{tabular}{|l|l|}
\hline Voltage (V) & 25 \\
\hline Current (I) & 300 \\
\hline Welding speed (mm/sec) & 3.33 \\
\hline Plate thickness (mm) & 11 \\
\hline Heat input $(\mathrm{J} / \mathrm{mm})$ & 2240 \\
\hline To & 25 \\
\hline $\mathrm{Tm}$ & 1590 \\
\hline
\end{tabular}

ELK Asia Pacific Journals - Special Issue

ISBN: 978-81-930411-8-5

\section{Peak Temperatures and cooling rates}

Peak Temperatures and cooling rates at different regions on weld were calculated which shown in figure 2 and 3 .

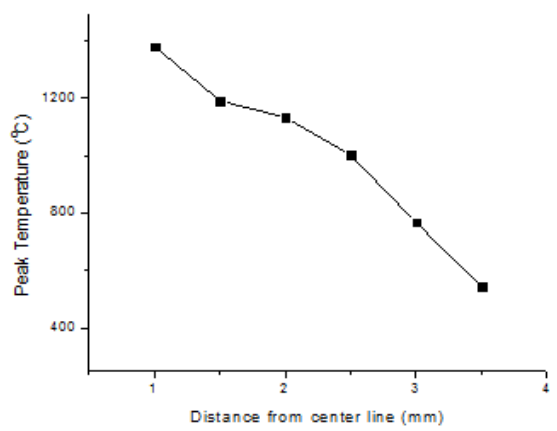

Fig.2 . Peak temperatures Vs. distance from center line

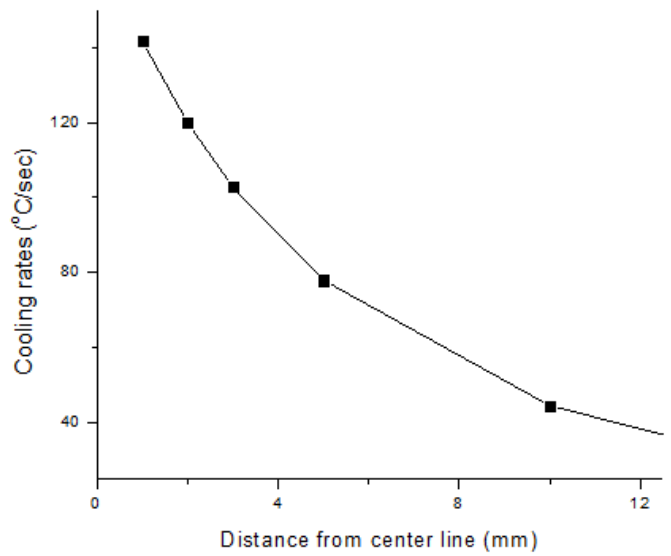

Fig. 3.Cooling rates VS Distance from center line

The theoretical temperature profiles were found to be match with practical SAW process. These temperature profiles were further accustomed to compare the temperature profile used for HAZ simulation.

\section{E. Heat Affected Zone (HAZ) Simulations}

The peak temperatures for the HAZ simulations were selected in reference to the acquired dilatometer data and are provided in Table 3 [6].

Table 3 Peak Temperature of different HAZ Regions.

\begin{tabular}{|l|l|l|}
\hline HAZ Regions & Location & Peak Temperature $\left({ }^{\circ} \mathrm{C}\right)$ \\
\hline SCHAZ & T< Ac1 & 650 \\
\hline ICHAZ & Ac1<T<Ac3 & 750 \\
\hline FGHAZ & T $>$ Ac3 & 950 \\
\hline CGHAZ & T $>$ Ac3 & 1300 \\
\hline
\end{tabular}


Solid bar samples having rectangular shape of $70 \mathrm{~mm}$ (in length), $11 \mathrm{~mm}$ (thickness) and $11 \mathrm{~mm}$ (in width) were used for the simulations. Two weld cooling rates were simulated (i) A faster cooling rate to simulate LHI welding conditions with no preheat, and (ii) A slower cooling rate to simulate $\mathrm{HHI}$ welding conditions with a moderate preheat temperature. The cooling rates were achieved through the selection of grip sets. A standard copper grip set was used for the LHI simulations. For the HHI simulations, a stainless steel grip set that provided minimal contact at the ends of the sample was used. The average $t 8 / 5$ times, where $t 8 / 5$ represents the cooling time from $800^{\circ} \mathrm{C}$ to $500^{\circ} \mathrm{C}$, were $10 \mathrm{~s}$ and $43 \mathrm{~s}$ for the $\mathrm{LHI}$ and $\mathrm{HHI}$ simulations, respectively [7]. The $t 8 / 5$ is a long-established index of the cooling rate of the weld thermal cycle for steels. The thermal-cycle simulations were conducted with the Gleeble chamber in high vacuum of approximately $10^{\wedge}-6$ torr $\left(1.3 \times 10^{\wedge}-4 \mathrm{~Pa}\right)$ to limit sample surface oxidation and thermocouple detachment. The simulated welding thermal cycle was calculated by Rosenthal's heat flow [8].

\section{F. Peak Temperatures calculation using Exponential Equation}

Thermal cycle which is used in Gleeble for CGHAZ and FGHAZ are represented in figures 4 and 5.given below. And similar cycle used for ICHAZ and SCHAZ.

$\mathbf{T}=\mathbf{T}_{\max } \mathbf{e}^{(-0.47 t / \Delta t)}$

Where,

$\mathrm{T}_{\max }=$ Peak Temperature

$\Delta \mathrm{t}=$ Cooling time $(800-500)$

$\mathrm{T}=$ time $(\mathrm{sec})$

The peak temperature profiles which were used in Gleeble simulation for HAZ simulation calculated by exponential equation. The exponential equation was taken from Gleeble Hand book. The calculated values of Temperature for LHI and HHI are shown in figure.

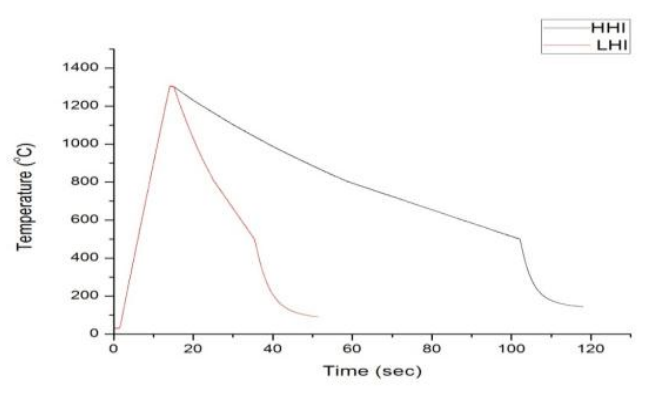

Fig. 4 Variation of Temperature with time of CGHAZ

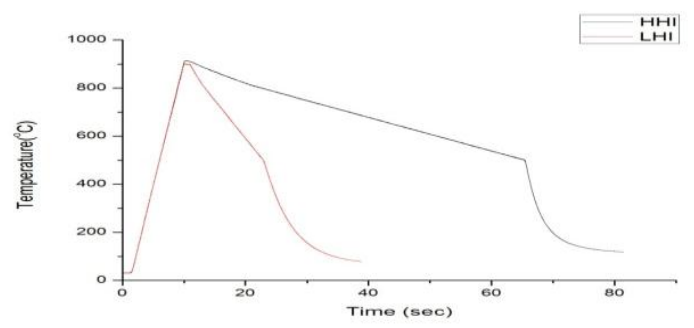

Fig. 5. Variation of Temperature with time of FGHAZ

\section{RESULTS AND DISCUSSION}

\section{A. Charpy $V$ notch Impact Test Analysis}

The Charpy V notch impact energy values for each test condition are given in Table. The Impact energy vs. different regions of $\mathrm{HAZ}$ plots at $25^{\circ} \mathrm{C}$ and $-40^{\circ} \mathrm{C}$ are shown in Figure (6) and figure (7).

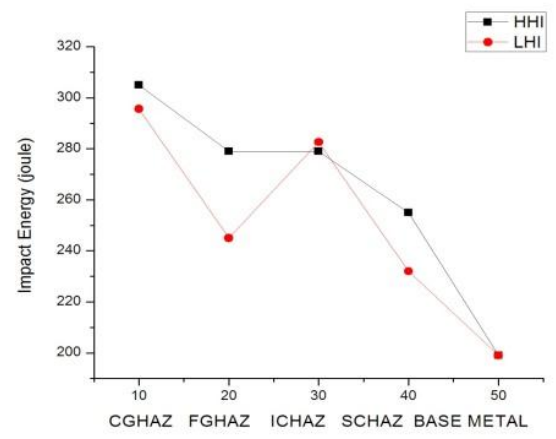

Fig. 6. Impact energy at different $\mathrm{HAZ}$ at $25^{\circ} \mathrm{C}$

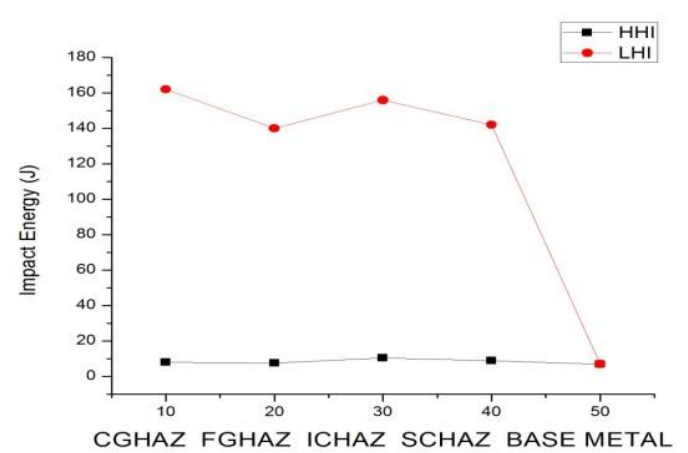

Fig. 7. Impact energy at different $\mathrm{HAZ}$ at $-40^{\circ} \mathrm{C}$

\section{B. Microstructure Characterization}

The Optical micrographs of the microstructures of API 5L X52 represent major portion ferrite and minor portion of pearlite. The microstructures of the base metal, LHI and HHI samples are shown in figures. Each region for LHI consists of lath martensite (LM) typical of low carbon steels. The simulated ICHAZ and FGHAZ microstructures consist of much finer lath martensite (LM) compared to the CGHAZ. The ICHAZ microstructure also consists of some darker lath martensite. The SCHAZ microstructure exhibits a microstructure similar in appearance to the BM microstructure. In each micrograph the major phases are clearly shown. Each region for HHI consists of upper bainitic (UB) phase. In CGHAZ (HHI) major portion consist of acicular ferrite, widmanstatten ferrite (WF), upper bainite and pearlite $(\mathrm{P})$. Polygon ferrite $(\mathrm{PF})$, inter granular ferrite (GF) and acicular ferrite (AF) phases are presented which are shown in respective Figures. In ICHAZ (HHI), major portions are acicular Ferrite. These all phases in different simulated samples are validated by the following reference papers [9$13]$. 


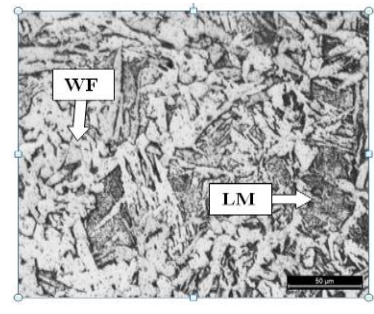

Fig. 8 . CGHAZ (LHI)

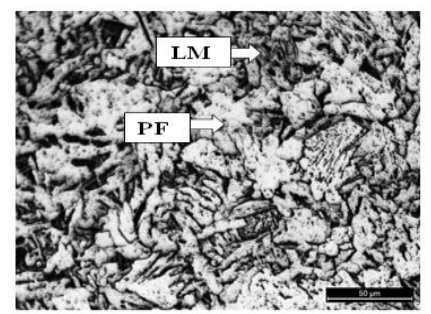

Fig. 10. FGHAZ (LHI)

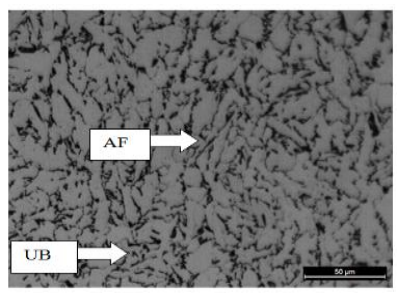

Fig. 12 .ICHAZ (HHI)

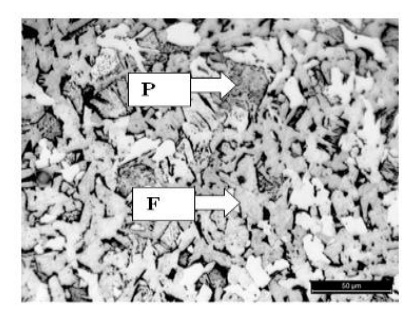

Fig. 14 SCHAZ (LHI)

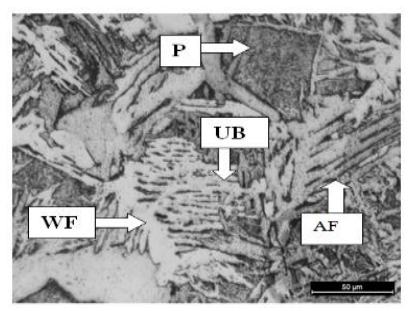

9. CGHAZ (HHI

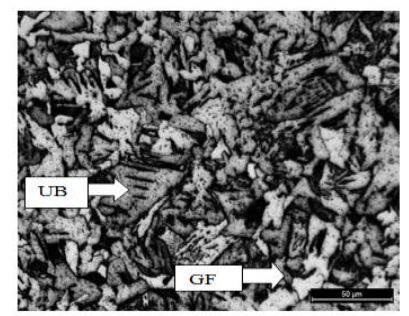

Fig.11 . FGHAZ (HHI)

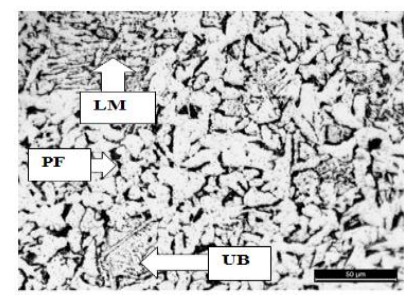

Fig. 13. ICHAZ (LHI)

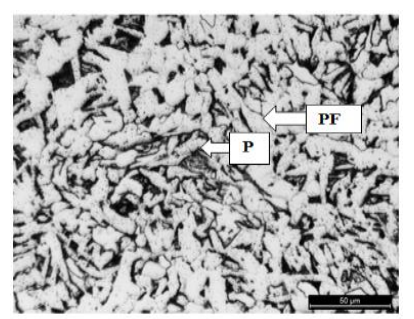

Fig.15. Base metal

\section{Micro Hardness Measurement}

Micro hardness values were measured at different regions on weld HAZ for both LHI and HHI conditions are shown in Table 4.

Table4. Vickers Hardness values at different regions

\begin{tabular}{|l|c|}
\hline Different regions & Average Vickers values(HV) \\
\hline Base Metal & 198 \\
\hline CGHAZ (HHI) & 173 \\
\hline CGHAZ (LHI) & 178 \\
\hline FGHAZ (HHI) & 175 \\
\hline FGHAZ (LHI) & 184 \\
\hline ICHAZ (HHI) & 230 \\
\hline ICHAZ (LHI) & 242 \\
\hline SCHAZ (HHI) & 206 \\
\hline SCHAZ (LHI) & 211 \\
\hline
\end{tabular}

A plot of Vickers micro hardness vs. different HAZ regions for the API 5L X52 simulated HAZ samples is provided in Figure 16. The Vickers hardness profile for the different HAZ regions is similar for both the LHI and HHI conditions with a slightly higher hardness observed in the LHI samples for each HAZ region. A hardness peak was observed in the ICHAZ with the lowest hardness occurring in the CGHAZ.

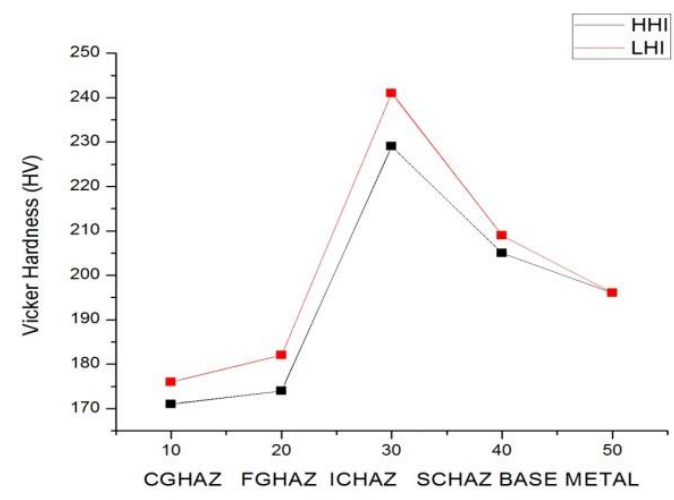

Fig. 16. Vickers Hardness variation with different HAZ

The hardness of the SCHAZ and FGHAZ samples was found to be slightly lower than the BM. This reaffirms the Gleeble HAZ simulation technique as an accurate method to simulate HAZ regions.

\section{Discussion}

The simulated HAZ samples were shown to have better impact toughness than the $\mathrm{BM}$ at both test temperatures, suggesting that there is not any kind of toughness loss in the weld HAZ regions in an actual weld. The toughness values of the ICHAZ, FGHAZ, and CGHAZ regions are inversely correlated with the measured hardness values of these regions, and are also above the toughness values for the $\mathrm{BM}$ and SCHAZ regions. The BM and SCHAZ regions also exhibited a slight decrease in toughness that was not observed in the ICHAZ, FGHAZ, and CGHAZ regions when tested at a lower temperature of $-40^{\circ} \mathrm{C}$ The maintenance of good toughness for the HAZ regions at low temperatures can be partially attributed to the formation of retained austenite in the HAZ microstructures, which has been shown to have a beneficial effect on toughness. These toughness values of different simulated samples are validated by following reference paper $[10,12]$. The effect of retained austenite has been attributed to acting as a sink for elements deleterious to fracture toughness such as carbon, and in disrupting the crystallographic alignment of the martensite packets. The overall results suggest that the liquid nitrogen quench intended to form precipitated austenite in the BM are not necessary to obtain adequate properties. The finer packet size in the ICHAZ and FGHAZ regions would be expected to provide better toughness at both room temperature and $-40^{\circ} \mathrm{C}$ which were clearly investigated in the present work. In Figure 17, the impact energy values determined at $25^{\circ} \mathrm{C}$ temperature are plotted against the average hardness of the single-pass HAZ regions. 


\section{Acknowledgment}

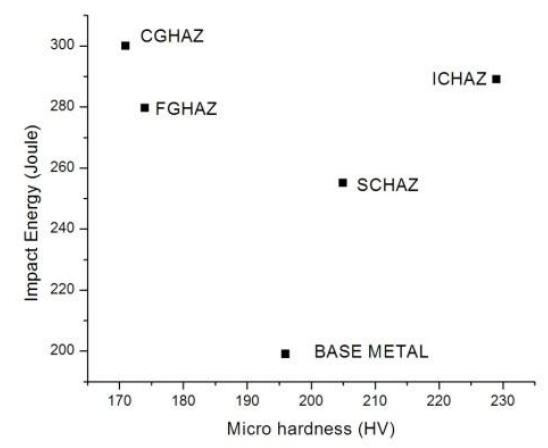

Fig. 17. Variations of Impact Energy with Micro Hardness

\section{CONCLUSIONS}

- In the SAW Process, the measured HAZ hardness has a minimum of $171 \mathrm{HV}$ in the CGHAZ (HHI) directly adjacent to the FZ boundary, increasing to a maximum of $241 \mathrm{HV}$ in the ICHAZ (LHI) region.

- HAZ regions have exhibited higher toughness than the $\mathrm{BM}$ at both test temperatures of $25^{\circ} \mathrm{C}$ and $-40^{\circ} \mathrm{C}$.

- The highest toughness at both temperatures was exhibited by the CGHAZ (HHI), with fracture toughness values of $300 \mathrm{~J}$ at $25^{\circ} \mathrm{C}$

- The BM and HAZ regions exhibited quasi-cleavage fracture at $-40^{\circ} \mathrm{C}$.

- Higher toughness values correlated with lower hardness, with the exception of the ICHAZ region, exhibited both hardness and toughness increase compared to the BM.

- Each region for LHI consists of lath martensite typical of low carbon steels. The ICHAZ and FGHAZ microstructure consist of much finer Lath martensite compare to CGHAZ.In the ICHAZ microstructure major portion consist of acicular ferrite.
Authors are thankful to Director, CSIR-National Metallurgical Research Laboratory to permit publishing of this work.

\section{References}

[1] T. Mohandas, G. Madhusudan Reddy, B. Satish Kumar, J. Mater. Process.Technol. 88 (1999) pp.284.

[2] V.F. Zackay, E.R. Parker, R.D. Godsy, W.E. Wood, Nature-Physical Science 236 (1972)pp.108.

[3] Nippes, E.F., Savage, W.F., Allio, R.J., 1957 Weld. J., 36 (12) (1957),pp. 531-540.

[4] S. Uhm, J. Moon, C. Lee, J. Yoon, B. Lee, ISIJ Int. 44 (7) (2004) pp.1230.

[5] Welding Hand book, vol. 1, Welding Science and Technology. Miami, FL: American Welding Society, Ninth ed., 2001, pp.90-120.

[6] D. Yapp and S. Blackman, Journal of the Brazilian Society of Mechanical Sciences and Engineering, vol.26, No. 1 2004,pp. 89-97.

[7] K. Easterling, Introduction to the Physical Metallurgy of Welding. Oxford UK: Butterworth-Heinemann, 1992.

[8] K. Easterling, Introduction to the Physical Metallurgy of Welding, Butterworths, 1983, pp.20, 33-36, 42

[9] H, Oshige H \&Tanoe T (1980) Effect of martensite-austenite constituent on HAZ toughnessof high strength steel. Transactions of the Japan Welding Society 11 October pp. 3-12.

[10] Lee JL \& Pan YT (1991) Microstructure and toughness of simulated heat-affected zone in $\mathrm{Ti}$ - and $\mathrm{Al}$-killed steels. Materials Science and Engineering A 136 (4): pp.109-119.

[11] Lee JL \& Pan YT (1995) The formation of intragranular acicular ferrite in simulated heat-affected zone. ISIJ International 35 (8): pp. 1027-1033.

[12] Yamamoto K, Matsuda S, Haze T, Chijiiwa R \& Mimura H (1989) A new developed Ti-oxide bearing steel having high HAZ toughness. Proc. Symposium on Residual and Unspecified Elements in Steel, ASTM STP 1042, Philadelphia 1989. Eds. Melilli A.S. \&Nisbett E.G. American Society for Testing and Materials: pp. 266-284.

[13] Terada Y, Chijiiwa R, Tamehiro H, Kikuma T \&Funato K (1992) Titanium-oxide bearing steels for offshore structures. Proc. 2nd International Conference on HSLA Steels, Beijing, 1990.Eds. Tither G. \&Shouma Z. The Minerals, Metals \& Materials Society: pp. 519-524. 